MARKETING AND BRANDING
RESEARCH $\begin{gathered}\text { INDUSTRIAL } \\ \text { MANAGEMENT } \\ \text { INSTITUTE }\end{gathered}$

\title{
A MCDM approach for supplier selection process: A pilot study from Iran
}

\author{
Babak Daneshvar Rouyendegh*, Farshid Gholamrezanezhad \\ Department of Industrial Engineering, Atılım University, İncek, Ankara, Turkey
}

\begin{tabular}{|c|c|}
\hline & ABSTRACT \\
\hline $\begin{array}{l}\text { Keywords: } \\
\text { Supply Chain } \\
\text { Management, Multi- } \\
\text { Criteria Decision- } \\
\text { Making, Technique for } \\
\text { Order of Preference } \\
\text { by Similarity to Ideal } \\
\text { Solution } \\
\text { Correspondence: } \\
\text { babek.erdebilli@atilim }\end{array}$ & $\begin{array}{l}\text { This paper utilized TOPSIS method to implement and select a proper supply chain } \\
\text { management system (SCMs). SCM selection was figured out and evaluated by applying } \\
\text { multi-criteria decision-making (MCDM) methods. The study employed an evaluation } \\
\text { methodology based on the technique for order preference by similarity to ideal solution } \\
\text { (TOPSIS). The supplier selection problem is solved utilizing the TOPSIS method and then it } \\
\text { was used to determine the weights of all criteria by considering the effects of interference } \\
\text { and the relationships among the selection criteria. The current methodology provided a } \\
\text { proper and easy ranking system of supplier variables using a TOPSIS method which was } \\
\text { considered as the ultimate goal of any effective SCM system and was clarified with a } \\
\text { numerical example. }\end{array}$ \\
\hline
\end{tabular}

CAIMI Journals

\section{Introduction}

A supply chain (SC) is a framework of systems, people, technologies, general information, and resources concerned with shifting a product or service from supplier to client. In this processes, SC converts natural resources or raw materials and elements into a finished products or goods in order to be shifted to the clients. Today, technological improvement in the markets and global competittive environmentsforce organizitions to optimize their operational processes and procedures. Having a highly competitive and effective SCM is considered as vitalfactor fororganizational success. Global competitors force organizations to make optimizations not only atorganization-wide level, but also with regard to the supplier, purchaser, and logistic channels.In the early 1980s, SCMs were improved to combine key 
business processes between customers and suppliers to ensure better quality for goods, services, and customers' required information. The basic aim of SCM is to satisfy customers by effective use of sources, capacity distribution, stock, and labor.

\section{Method}

According to fuzzy TOPSIS method, $m$ decision- making units (DMUs) were calculated according to $n$ criteria. The TOPSIS method is figured out based on the concept that the chosen DMUs should present both positive and negative ideal solutions (PIS/NIS) (Hwang \& Yoon, 1981). Also, these DMUs should have the shortest Euclidean distance from the PIS andthe farthest Euclidean distance from the NIS. Each criterion is supposed to have a utility function that is monotonically increasing or decreasing.TOPSIS was improved by Hwang and Yoon in 1981 as DMUs in the ELECTRE method. The basic concept of this method is to calculate the efficiency of DMUs through the similarity to ideal solution and the furthermost distance from the NIS in a geometrical sense (Ertugrul \& Karakasoglu, 2009; Hwang \&Yoon, 1981).Generally, the PISs and the NISs are composed of all the best scores and all the worst scores which can reach to the criteria (Krohling \& Campanharo, 2011, Rouyendegh, 2015). According to the entropy method, the idea of deriving weights tries to evaluate the weight without all relevant interventions of the decision-makers. The importance of these criteria is that they carry the direct function of information to the whole set of decision making units (DMUs). Employing the entropy method to derive the weight is based on the concept that a criterion is more significant if there is a greater spreading in the measurements of DMUs. The supremacy of applying the entropy method for obtaining the weights of criteria is that it eliminates the subjectivity of decision makers (DMs) in calculating the weights, includes objective evaluations, and gives an advantage when DMs disagree on the scores and weights (Song, Minga, Wua,\& Zhua, 2013). Optimal goal weights are acquired by utilizing the entropy method. According to decision matrix, entropy is distributed in this procedure to evaluate DMUs based on each criterion. The results of determining the target weight of the sub-criteria above the DMU level and utilizing entropy can be summarized in the steps including identifying the pair-wise comparisons and constructing a decision matrix,determining the normalized decision matrix (NDM), determine the weighted normlized a decision matrix (WNDM),determining a positive ideal solution (PIS) and negative ideal solution (NIS),determining the seperation of each DMU,and determining relative closeness to the ideal solution.

The first step which identify thepair-wise comparisons and construct a decision matrixcan create feasible DMUs and calculate the criteria. Suppose that there are $\mathrm{m}$ alternatives, $n$ evaluation criteria, and $\mathrm{k}$ DMs in a decision making problem. A framework model is set to calculate the pair-wise comparisons for each level of hierarchy through utilizing pair-wise relations that evaluated by analytical hierarchy process (AHP) and introduced by Thomas Saaty (1980).Table 1 presents these fundamental scales. 
Table 1

The Fundamental Scales

\begin{tabular}{cc}
\hline Importance Intensity & Definition \\
\hline 1 & Equal Significance \\
3 & Moderate Significance of One over Another \\
5 & Strong Significance of One over Another \\
7 & Very Strong Significance of One over Another \\
9 & Extreme Significance of One over Another \\
\hline
\end{tabular}

The following evaluation matrix includesmalternatives (DMUs) and $n$ criteria with with the intersection of each guidance of each DMU and criteria. Where $x_{i j}$ demonstrates the performance of the $i^{\text {th }}$ DMU in terms of the $j^{\text {th }}$ criteria (Triantaphyllou, Shu, Sanchez, \& Ray, 1998).

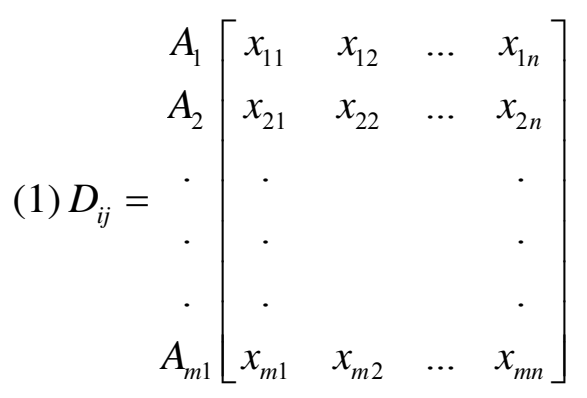

$i=1,2, \ldots, m ; j=1,2, \ldots, n$

In the second step, the normalized decision matrix (NDM) was determined. Moreover, matrix $\mathrm{R}$ is presented as follows:

$$
\begin{gathered}
r_{i j}=\frac{x_{i j}}{\sqrt{\sum_{k=1}^{m} x_{k j}^{2}}} \\
R_{i j}=\left[\begin{array}{cccc}
r_{11} & r_{12} & \ldots & r_{1 n} \\
r_{21} & r_{22} & \ldots & r_{2 n} \\
\cdot & & & \cdot \\
\cdot & & & \cdot \\
\cdot & & & \cdot \\
r_{m 1} & r_{m 2} & \ldots & r_{m n}
\end{array}\right]
\end{gathered}
$$

In the third step,theweighted normlizeddecision matrix (WNDM) was calculatedwhich is presented below. 
(4)

$$
V_{i j}=\left[\begin{array}{cccc}
w_{1} r_{11} & w_{2} r_{12} & \ldots & w_{n} r_{1 n} \\
w_{1} r_{21} & w_{2} r_{22} & \ldots & w_{n} r_{2 n} \\
\cdot & & & \cdot \\
\cdot & & & \cdot \\
\cdot & & & \cdot \\
w_{1} r_{m 1} & w_{2} r_{m 2} & \ldots & w_{n} r_{m n}
\end{array}\right]
$$

$V_{i j}=r_{i j} \otimes w_{j} j=1, \ldots, m, i=1, \ldots, n$

In the fourth step, the positive ideal solution (PIS) and negative ideal solution (NIS) are determined.In these formulas, $I$ and $J$ stand for the benefit criteria and the cost criteria, respectively.

$$
\begin{aligned}
A^{*} & =\left\{\left(\max _{i} v_{i j} \mid j \in J\right),\left(\min _{i} v_{i j} \mid j \in J^{\prime}\right\}\right. \\
\text { (6) } A^{-} & =\left\{\left(\min _{i} v_{i j} \mid j \in J\right),\left(\max _{i} v_{i j} \mid j \in J^{\prime}\right\}\right.
\end{aligned}
$$

The fifth step is used to determineand seperate each DMU. This is done by using the PIS and NIS.

$$
\begin{aligned}
& S_{i}^{*}=\sqrt{\sum_{j=1}^{n}\left(v_{i j}-v_{j}^{*}\right)^{2}} \\
& \text { (7) } S_{i}^{-}=\sqrt{\sum_{j=1}^{n}\left(v_{i j}-v_{j}^{-}\right)^{2}}
\end{aligned}
$$

The last step is used todetermine the relative closeness of alternatives to the ideal solutions.

$$
\text { (9) } C_{i}^{*}=\frac{S_{i}^{-}}{S_{i}^{-}+S_{i}^{*}}
$$

According to the value of closeness coefficient for each alternative, the ranking order of all thealternatives can be determined from the highest closeness coefficient to the lowest. The alternative with the highest closeness coefficient is obviously considerable.

This study was conducted to identify the majority of algorithms in the literature. It refered to an important aspect of the DMUwhich was data collectionsince the properties of data needed for theselection process highly affected the usability and trustability of any models to be used in the selection process. Furthermore, this study offered a comprehensive system for choosing the right SCM system in Iranian industry based on MCDMs. The experts' opinions 
were taken from the related sectors. As a summary of case study, data was collected and analysed via surveys. The main criteria for SCM system of an Iranian petroleum industry are cost/price, time, quality, equipment, and distance. Supplier 1 referred to the leader of petrol market in SCM. It was considered as one of the Iran's largest independent suppliers with more than 10,000 employees across the nation. Supplier 2 referred to an easy-to-use and comprehensive SCM framework which covered medium-sized organizations. Supplier 3 and supplier 4 were public companies that supply and implement the job application for the petroleum industry sector.

\section{Results}

The implementation of TOPSIS method became possible through applying the algorithm. Table 2 indicates to the main criteria of SCMs including cost/price, time, quality, equipment, and distance.

Table 2

The Main Criteria of SCM Systems

\begin{tabular}{cccccc}
\hline Suppliers & Cost/Price & Time & Quality & Equipment & Distance \\
\hline Supplier 1 & 160 & 24 & 18 & 14 & 520 \\
Supplier 2 & 150 & 28 & 18 & 18 & 460 \\
Supplier 3 & 144 & 26 & 14 & 10 & 100 \\
Supplier 4 & 130 & 30 & 10 & 10 & 280 \\
& Cost/Price & Time & Quality & Equipment & Distance \\
Supplier 1 & 0.27 & 0.22 & 0.30 & 0.26 & 0.38 \\
Supplier 2 & 0.25 & 0.25 & 0.30 & 0.34 & 0.33 \\
Supplier 3 & 0.24 & 0.24 & 0.23 & 0.19 & 0.07 \\
Supplier 4 & 0.22 & 0.27 & 0.16 & 0.19 & 0.20 \\
\hline
\end{tabular}

$$
\left[\begin{array}{lllll}
0,546 & 0,443 & 0,586 & 0,522 & 0,689 \\
0,512 & 0,517 & 0,586 & 0,671 & 0,609 \\
0,492 & 0,480 & 0,456 & 0,373 & 0,132 \\
0,444 & 0,554 & 0,326 & 0,373 & 0,371
\end{array}\right] \times\left[\begin{array}{ccccc}
0,07 & 0 & 0 & 0 & 0 \\
0 & 0,003 & 0 & 0 & 0 \\
0 & 0 & 0,14 & 0 & 0 \\
0 & 0 & 0 & 0,15 & 0 \\
0 & 0 & 0 & 0 & 0,60
\end{array}\right]=\left[\begin{array}{ccccc}
0,038 & 0,0013 & 0,082 & 0,083 & 0,413 \\
0,036 & 0,0015 & 0,082 & 0,010 & 0,365 \\
0,034 & 0,0014 & 0,064 & 0,056 & 0,079 \\
0,031 & 0,0017 & 0,046 & 0,056 & 0,223
\end{array}\right]
$$

$$
\begin{aligned}
& V_{j}^{+}=\left[\begin{array}{lllll}
0,031 & 0,0013 & 0,082 & 0,083 & 0,079
\end{array}\right] \\
& V_{j}^{-}=\left[\begin{array}{lllll}
0,038 & 0,0017 & 0,046 & 0,010 & 0,413
\end{array}\right] \\
& d_{1}^{+}=0,335, d_{2}^{+}=0,295, d_{3}^{+}=0,337, d_{4}^{+}=0,198 \\
& d_{1}^{-}=0,333, d_{2}^{-}=0,060, d_{3}^{-}=0,338, d_{4}^{-}=0,191
\end{aligned}
$$

$c_{1}=0,499, c_{2}=0,169, c_{3}=0,500, c_{4}=0,491$

The TOPSIS method was utilized in four types of SCMs. Table 3 shows the results of TOPSIS method. Based on the obtained results, $\mathrm{SCM}_{1}$ allocated the $2^{\text {nd }}$ rank to itself while $\mathrm{SCM}_{4}, \mathrm{SCM}_{3}$, and $\mathrm{SCM}_{4}$ assigned the $3{ }^{\text {rd }}, 1^{\text {st }}$, and the $4^{\text {th }}$ rank to themselves, respectively. 
According to Table 2, $\mathrm{SCM}_{3}$ is considered as the most significant $\mathrm{SCM}$ among the four available types. In Table 3, the second column shows the scores of four types of SCMs. As these scores got better, their rankings also improved. According to Table 3, $\mathrm{SCM}_{3}$ has the largest value (0.50) because it provides the highest efficiency and performance and $\mathrm{SCM}_{2}$ has the lowest value (0.16).

Table 3

The Result of TOPSIS Model

\begin{tabular}{lcc}
\hline $\mathrm{SCM}$ & Score & Rank \\
\hline $\mathrm{SCM}_{1}$ & 0.49 & 2 \\
$\mathrm{SCM}_{2}$ & 0.16 & 4 \\
$\mathrm{SCM}_{3}$ & 0.50 & 1 \\
$\mathrm{SCM}_{4}$ & 0.49 & 3 \\
\hline
\end{tabular}

\section{Conclusion}

The goal of this paper was to identify thedata sets related to SCM selection. It tried to have a glance at the evaluation of SCM through creating a system regarding the TOPSIS model. The results were considered to be the most important in developing our knowledge of the SCM system in Iranian petroleum industries. The main criteria were cost/price, time, quality, equipment, and distance.The appliedTOPSIS model in this study was considered to berelatively easy to utilizeand applicable to any number of DMUs. This model can also be used in evaluating management systems of health care organizations, entartiment industries, and related industries.

\section{References}

Ertugrul, I., \& Karakasoglu, N. (2009). Performance evaluation of Turkish cement firms with fuzzy analytic hierarchy process and TOPSIS methods. Expert Systems with Applications, 36(1), 702-715.

Hwang, C. L., \&Yoon, K. (1981). Multiple attribute decision making: Methods and applications. New York, NY: SpringerVerlag.

Krohling, R. A., \& Campanharo, V. C. (2011). Fuzzy TOPSIS for group decision making: A case study for accidents with oil spill in the sea. Expert Systems with Applications, 38(4), 4190-4197.

Rouyendegh, B. D., \& Saputro, T. E. (2014). Supplier selection using integrated fuzzy TOPSIS and MCGP: A case study. Procedia-Social \& Behavioral Sciences., 116(21), 3957-3970.

Rouyendegh, B. D. (2015). Developing an integrated ANP and intuitionistic fuzzy TOPSIS model for supplier selection. Journal of Testing \& Evaluation, 43(3), 664-672.

Saaty, T. L. (1980). The analytical hierarchy process. New York: McGraw Hill.

Song, W., Minga, X., Wua, Z., \& Zhua, B. (2013). Failure modes and effects analysis using integrated weight-based fuzzy TOPSIS. International Journal of Computer Integrated Manufacturing,26(12), 1172-1186.

Triantaphyllou, E., Shu, B., Sanchez, S. N., \& Ray, T. (1998). Multi-criteria decision making: An operations research approach. Encyclopaedia of Electrical \& Electronics Engineering, 15, 175-186. 